\title{
ADAPTING SOCIAL DESIGN RESEARCH METHODS FOR SOCIALLY DISTANCED PRACTICE
}

\author{
Adela GLYN-DAVIES and Paul RUSSELL \\ University of Derby
}

\begin{abstract}
Social Design Research, due to its interactive and democratic nature, typically requires access to participants at all stages of the Design process (enquiry, insight gathering, ideation, and testing). This ensures that the designers' practice is informed with contextual knowledge gained through relationshipbuilding and ethnography, which are key features of Social Design Research [1]. Due to the impact of the COVID-19 pandemic, the delivery of Design education, and the approaches taken by lecturers and students had to adapt. The methods, attitudes and approaches to Design research and practice have evolved due to these changes due to the use of newly adopted digital collaborative environments. This paper presents the adaptations to existing Social Design Research methods and new ones which have been generated by the students through the undertaking of a project aimed at designing for social value delivered to first year Product Design students at The University of Derby.
\end{abstract}

Keywords: Social design, design for social innovation, design research methods

\section{INTRODUCTION}

As designers, consultancies [2] and publicly funded design organisations [3] increasingly acknowledge the potential for Design to positively contribute toward social impact, Social Design is becoming an essential part of Product Design curriculums around the world to prepare students for evolving practice. The necessity to challenge values and attitudes to Design has been made more evident after the Social Turn [4] and its push for communities taking part in the creative process. The catalyst for this new emphasis on a more considered, holistic approach to Design can be viewed as a reaction to established paradigms which centralise market returns, user experience and the consumption of goods [5]. Over reliance on Design as a tool to fulfil immediate needs and wants, has led to unsustainable solutions, with negative implications for human beings and the environment. Therefore, designers sought to utilise Design to address the broader and more complex issues facing humanity and thus generate a new, more socially conscious approach to Design. Social Design is understood as Design both for and with society [3,5] and it requires designers to undertake thorough qualitative research which involves engagement, participation, and collaboration $[5,6]$.

\subsection{Social Design Research}

The open and inclusive approach to research in a Social Design framework allows students to learn about the daily pattern of conduct of a community; how they might use their spaces (public/private); what kind of experiences might shape their daily lives and what challenges they face [6-10]. Social Design necessitates habituated practice, shaped and driven by knowledge of a group's shared experience as a driving factor in designing for greater value and impact. [10,12]. Social Design Research relies on primary qualitative research, which seeks to obtain and understand culturally specific information about the values, attitudes, opinions, and behaviours of a particular community/audience in its social context [13]. The advantage of this type of enquiry lies in its ability to provide multi-faceted descriptions of how people experience a given issue, situation, or circumstance. Social Design Research investigates and provides information about the 'social' side of an enquiry and focuses on experiential factors of a community; this includes lived, shared, and learned experience [10-13].

\subsection{Effects of the 2019 COVID-19 pandemic on students' learning}

With the implementation of national lockdowns, University curriculums had to quickly adapt to a digital learning environment. For Social Design modules this meant that all stages of the creative 
process, which entails working for and in a community, was disrupted because they could no longer undertake primary face-to-face research. This moved students away from working in physical spaces with communities and consequently isolated them and the community participants to mainly virtual spaces. As part of the project undertaken by the Product Design year 1 students, they were briefed to co-design urban furniture for a local park which could be manufactured by members of the local communities with migration background, who would at the end of the project gain a skills certificate. Due to the collaborative nature of the project, students were required to undertake Design ethnography and work together to explore how to best address the needs of the park while retaining simplicity of their designs for the participants which will be making them. Realisation of the project would thus create a skill share initiative where both parties exchange knowledge and create a more welcoming and accessible environment at the park for migrant communities and the local student population.

As a result of the pandemic and social distancing regulations the university implemented a programme of blended learning. Blended learning is a mixture of online and face to face learning, occurring in an instructional based context both in the classroom and over digital meeting spaces [13].

\section{RESEARCH METHODS}

\subsection{Social Design Research Methods}

The main two research methods which students were encouraged to use for Social Design briefs at the university are Design Ethnography and Spatial Studies.

\subsubsection{Design Ethnography}

Ethnography as a method seeks to enable designers to understand the potential users of resulting designs, how they might perceive, access, and engage with them $[14,15]$. It grants designers in-depth, empathic knowledge of the lifestyle, routines and issues which matter most to the participants (See Figure 1 below). This enables designers to develop ideas whilst clearly understanding who they are designing for. Evolutions within this approach have taken it from participant observation to interaction, conversation, and Co-Design. Common ways of collecting data used within this method include 'SemiStructured Surveys' and 'Interactive On-Site Enquiries'.

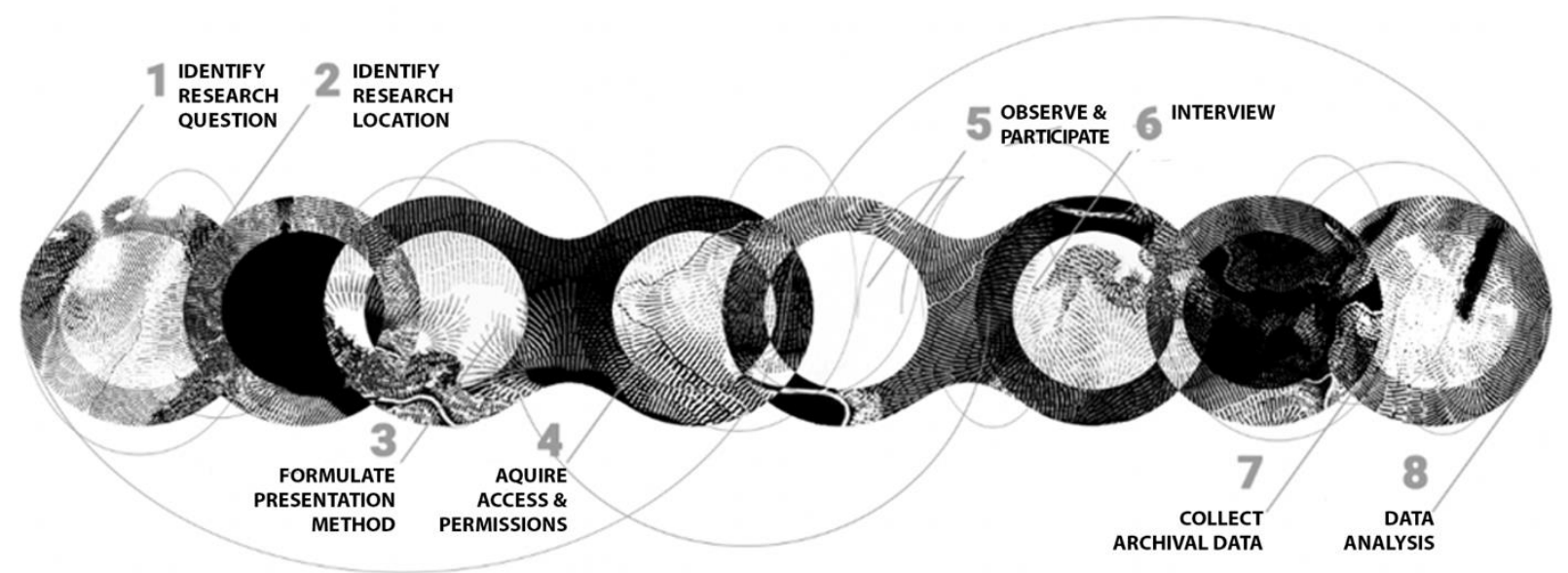

Figure 1. Ethnographic research model taught as part of Social Design modules.

Semi-Structured Surveys in Social Design Research are not used in their common form (e.g., questionnaires seeking a quantifiable set of data from participants), instead they are used in a semistructured way, allowing for open conversation combined with fixed questions. As opposed to gaining a small subsection of data which translates broadly to a population, Social Design surveys are components of a carefully planned ethnography, helping Design researchers to understand specific communities.

Interactive On-Site Enquiry is a form of observation which requires being physically present in the setting or amongst the community. It can take the form of workshops, collaborative Design thinking 
sessions and observations. It is a means of gathering primary data from an environment without doing a survey. The involved nature of this approach means that it needs to be evaluated within an interpretative framework as opposed to a scientific one.

\subsubsection{Spatial Studies}

Spatial Studies entails examining the geography and urban planning of a space [16]. In a Social Design brief, the data is typically collected in two ways; first by gathering the geographical data, e.g., obtaining the specific boundary statistics, understanding the relevant spaces and places where a community interacts. This type of data is often portrayed in descriptive forms such as maps and schematics. Furthermore, spatial data is used to examine patterns of behaviour, amalgamating spatial data into research analysis [16]. By using maps and schemes as tools for identifying patterns of behaviour and the interactions of a specific area with its surrounding environment, qualitative data can be systematically gathered and analysed, resulting in a better understanding of the social mapping of a community. Spatial data informs and supports ethnographic studies and allows designers to develop an illustrative, visual framework for community-environment interactions.

\subsection{Adaptation of Research Methods for Socially Distanced Practice}

\subsubsection{Methods Deemed Unsuitable for Socially Distanced Research}

The regulations for teaching during the pandemic and government enforced social distancing placed many difficulties on undertaking social research. All face-to-face enquiries were unable to go ahead due to health risks to both the public and students. Because there was no possibility to have interactive onsite enquiries at the park, which resulted in two major implications. Firstly, lockdown measures meant that students could only visit the park individually and not as groups, and they could not talk with visitors of the park. Secondly, it meant that students were unable to work with the community who live in the area, gain relationships, and begin to build an ethnographic profile of the people they were designing the products to be made by. Methods which were deemed unsuitable due to the pandemic included faceto-face interviews, field work which required students to meet up physically in groups, and on-site interactive structured and semi-structured surveys.

\subsubsection{Adapted Methods}

Whilst there were measures that completely prevented certain methods used in Social Design Research, it was possible to adapt others to fit the circumstances caused by the COVID-19 pandemic. For example, whilst it was impossible to perform surveys in-person, which can be more relational, it was possible to use digital tools to connect with the community and elicit responses from them which could be analysed. Participants were recruited this way, not through attending the park and asking in-person but using social media networks (such as Facebook). Starting with friends and peers, and then branching out to friends of friends, the students were able to gather a sufficient sample size of regular park visitors from which insights could be gathered.

For Design Probes, several access factors were considered, which utilised new technologies to ensure understanding for migrant participants context contemplating language/cultural barriers. Students coordinated the creation of their surveys using interactive schemes of the park and animations. Translations were made available using cognate software which guided the users around a graphic display of a map of the park, indicating areas which they were required to answer questions about. Through individual trips to the park students built up a bank of photos and clips, along with access to topographic maps, which were then compiled into a more visual engaging survey which could be accessed from any internet capable device (See Figure 2 below). This provided students with feedback through questions, but also through clicks, recognising the areas of the park the community wanted to 'interact' with the most, albeit through a digital interface.

In the concept selection phase, the students also switched A-B testing from being in-person, to utilising web-hosted 3-D CAD models so that people could orbit around them and zoom into details.

\subsubsection{New Methods}

While moving to online delivery has caused complexity, it has also resulted in innovations of new collaborative research methods. Alongside this shift, the student's experience of studio learning took on completely new forms which had positive impacts despite the irregularities associated with moving 
promptly to online delivery. For example, students who might usually struggle to participate equally in group work in an on-campus environment, thrived when the burden of self-presentation was removed. Lecturers recognised these changes and value the democratisation of the groups, which can be a challenge in-person. To help facilitate their cohort relationships as peer designers, staff also encouraged the student groups to set up their own digital socialisation spaces. These took the form of digital 'Speakers' Corners', created on Microsoft Teams, Discord, Miro, and Mixer. Spaces like these, allowed students to contribute freely, collaborate and exact critique on each other's work, making sure that all students were involved, and the bond of the group was kept strong.

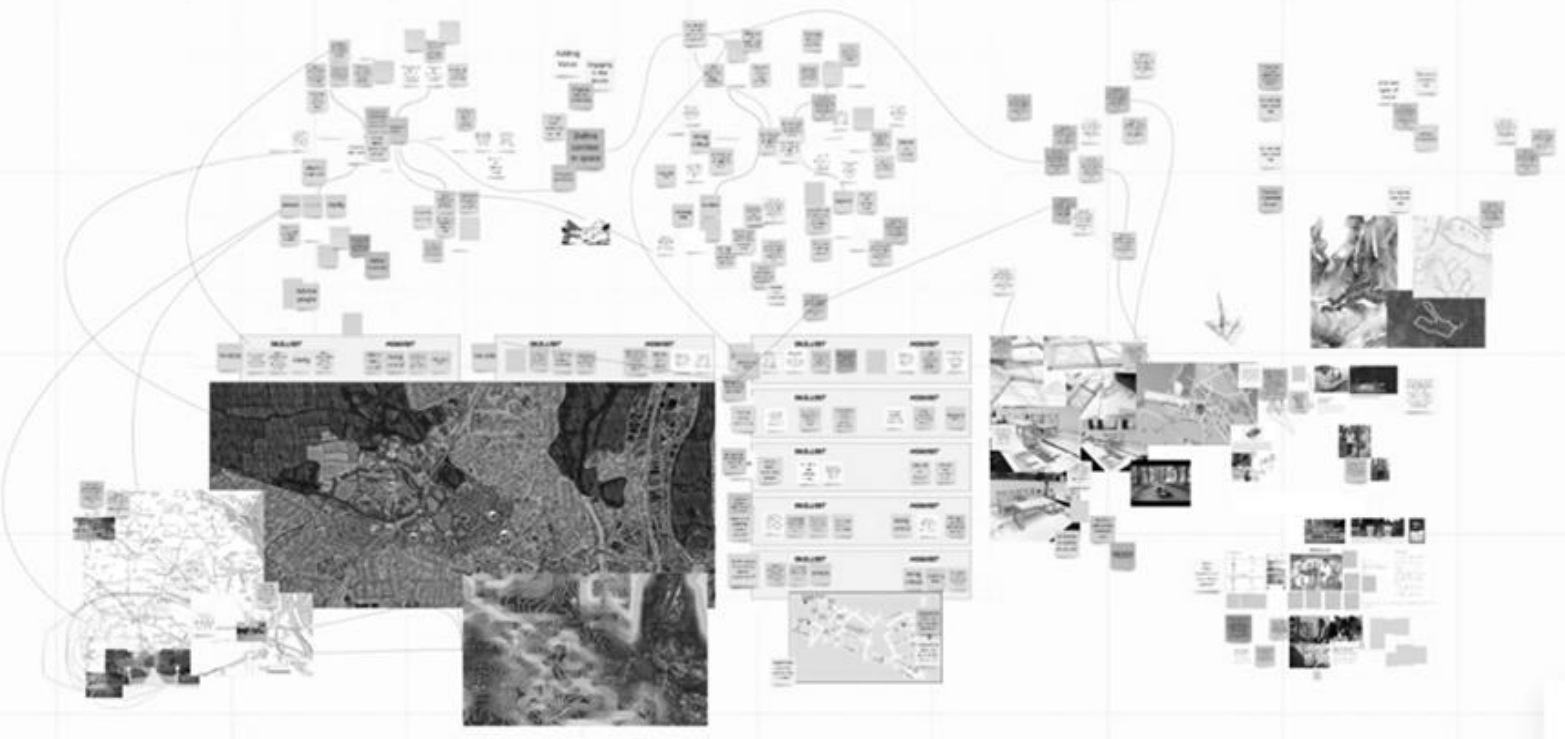

Figure 2. An example of digital collaborative spaces developed and utilised by students

Consequently, these formed an adapted method for their Social Design Research, which hereon is referred as 'Digital Speakers Corners', which allow for new ways of gathering data that still ensured integrity of research findings.

Another method which the students devised was a form of contextual enquiry where one team member acts as an "on-site navigator". The student carries a smartphone whilst in a video call to the other colleagues who are working from home who would record the site visit on their computers. This way the team-members who worked from their home-office could safely participate and enquire about the location without breaking social distancing rules, yet still be part of the directing of the gathering of information in real-time.

Alongside this, students also created hybrid methods for data mapping that relied on a blended enquiry, i.e., photographic, video evidence from the physical site and digital mapping data gathered from historic study libraries, satellite images and council databases.

\section{OUTCOMES}

\subsection{Facilitator perspective}

In response to the university's implementation of national health and safety measures, it is evident that some of the most innovative and effective rapid adaptations of Design Research methodologies and methods were generated by students. Upon the prompt adoption of digital workspaces, students adapted their approaches to undertaking, sharing, cross-evaluating, and working in groups. Each of these developments has created a push for a reconsideration and restructuring of teaching practice. As lecturers recognized that the break in physical socialization is impacting students' intrinsic and extrinsic motivations to learning, the need of digital spaces for socialization has become vital for healthy learning developments. First building blocks for these spaces were laid through real-time interactive online spaces such as Microsoft Teams collaboration channels and free online exhibition spaces. Once students started to use these spaces regularly as part of their online delivery and group research, the students themselves started to expand their digital social spaces through various gaming and Design platforms. The familiarity of these online spaces meant that students felt at ease to utilise these for broader 
purposes, such as group research, ideation, debates, as well as testing. Once these spaces were established, student groups organized open digital research groups, where participants of the communities could join from their mobile devices and take part in the data gathering, discussions and co-Design.

Due to lockdowns the majority of students were residing secluded in dormitories or family homes which meant that students did not have enough space to create prototypes in or even fabricate more refined product proposals. Lecturers recognized that these constraints would impact on students' technical development, therefore all access to campus, which was already heavily restricted and rigorously monitored, was dedicated to safe technical sessions. This allowed students to access materials and tools to produce rapid product prototypes and proposals. However, problems arose when these technical skills could not be shared physically with the participating community, leaving one part of the brief unsolved; the mutual knowledge and skill-sharing elements that would happen on site was no longer possible. This opened up speculative reflections on how these problems could be solved in the future through potential blended digital/ on-site co-Design sessions and the rethinking and restructuring of public spaces.

\subsection{Student perspective}

Whilst the blended environment has proven difficult and challenging to manage, students have responded exceptionally positively well to all the transitioning stages of learning. Although this learning experience was not able to grant students the same learning and social experience, it has revealed the potential of new learning structures that allow for a more progressive democratic curriculum, in which students can participate in the shaping of pedagogy as well as peer-to-peer and peer-to-academic learning.

Overall enthusiasm initially showed signs of diminishing when the learning fully progressed to onlineonly delivery as students felt isolated from their peers and struggled to structure their learning without the aspects of having physically to visit the campus or public spaces or interact directly with users of the park or migrant communities. Students who would usually confidently present and communicate their ideas started to be withdrawn from the online conversations and shared their progress only in written formats where students who would normally struggle to present in-person excelled in digital communities which allowed them to freely communicate as equals.

Once circumstances were more settled and the students had adapted and generated their new appropriate research methods and recruited enough participants, they started to manage their individual and team workloads well. This also led to the flattening of the participation hierarchy, which subsequently resulted in an improved experience for all students compared to strictly on-site collaboration approaches.

\section{FUTURE IMPLICATIONS}

Reflecting on the adaptations to research methods that evolved from implications caused by the national lockdown and public health and safety measures, it was evident that students are adaptable and Social Design Research can still be undertaken during times of social distancing. The students demonstrated that participatory and interactive research and practices can still be executed, and that digital realms of engagement can provide sufficient insights. Furthermore, the adaptations done within the span of less than one academic year implied that if the methods were further refined, they could be bettered, and new methodologies and methods for Social Design practice would likely emerge. This has confirmed the fact that regardless of the obsoletion of social distancing rules in the future, digital hybrids of Social Design Research methods will continue to be encouraged in student work.

\section{CONCLUSIONS}

The findings in this research-informed project could potentially open the discourse for the development of 'Digital Social Design' practice which provides a greater level of openness, inclusivity, and accessibility. This notion was proven as an equitable proposition for Product Design students, who managed to further their thinking and making skills even without daily access to machinery, studios, or public spaces in general. From this it is clearly implied that these new types of adaptations to learning and interacting have the potential to become part of curriculums and hybrid pedagogies past pandemic restrictions. Delivering academic Product Design curriculums in this way would give students greater freedom in managing their time outside of university schedules and generate more sustainable financial 
constraints that students face when having to travel to campus. Universities would have to consider supporting students with blended curriculums by providing technological support in forms of accessible machines and digital spaces of learning. Adaptations to blended learning have not just facilitated the development of new research methodologies in Social Design but also built up a new confidence within students that generated stronger comradery and congeniality. This has set a building block to a more sustainable community of learners that is increasingly tactful and resourceful with their time and abilities. Regardless of COVID-19 restrictions and their breakdown in the future, what was elucidated though this period is that students and lecturers were able to adapt to new circumstances which revealed the vulnerabilities of existing structures of Social Design Research.

\section{REFERENCES}

[1] Manzini E. Design When Everybody Designs: An Introduction to Design for Social Innovation. MIT Press; 2015.

[2] IDEO. Design for Social Impact: How to Guide [Online] 2014 [Cited: 2021 Mar 1] Available from: https://new-ideo-com.s3.amazonaws.com/assets/files/pdfs/news/IDEO RF Guide.pdf

[3] Design Council. Design for Public Good [Online] 2013 [Cited: 2021 Mar 1] Available from: https://www.designcouncil.org.uk/sites/default/files/asset/document/Design\%20for\%20Public\%2 0Good.pdf

[4] Bishop, C. The Social Turn: Collaboration and its Discontents [Online] Artforum International; 2006 [Cited: 2021 Mar 1] 44(6):178-183.

[5] Luke A. Design Activism's Teleological Freedoms as a Means to Transform our Habitus. Age of Alternatives Berlin; 2015

[6] Sachs A. Banz C. \& Krohn M. Social Design: Participation and Empowerment. Lars Müller Publishers/Museum für Gestaltung Zürich; 2018

[7] Press, M. \& Cooper, R. The Design Experience: The Role of Design and Designers in the $21^{\text {st }}$ Century. Bodmin: Ashgate Publishing; 2003.

[8] Papanek, V. Design for the Real World: Human Ecology and Social Change. Academy Chicago Publishers; 2005.

[9] Simon, H. Sciences of the Artificial. MIT Press, Cambridge; 1996

[10] Erlhoff, M. \& Marshall, T. Design Dictionary: Perspectives on Design Terminology. Birkhauser, Berlin; 2008.

[11] Margolin, V. \& Margolin, S. A "Social Model” of Design: Issues of Practice and Research [Online] Design Issues; 2002 [Cited: 2021 Mar 2] 18(4), 24-30.

[12] FHL International. Qualitative research Methods Overview [Online] 2011[Cited: 2021 Mar 2] Available from: https://course.ccs.neu.edu/is4800sp12/resources/qualmethods.pdf

[13] Bowyer, J. \& Chambers, L. Evaluating Blended Learning: Bringing the Elements Together. Research Matters, Cambridge; 2017.

[14] Jeffrey, L.M. Milne, J. Suddaby, G. \& Higgins, A. Blended Learning: How Teachers Balance the Blend of Online and Classrooms Components [Online] Journal of Information Technology Research; 2014 [Cited: 2021 Mar 3] 13:121-140.

[15] Van Dijk, G. Design Ethnography: Taking Inspiration from Everyday Life [Online] 2010 [Cited: 2021 Mar 3] Available from: https://www.stby.eu/wp 15/wcontent/uploads/2011/01/designet.pdf

[16] Bierbaum, A. \& Rucks-Ahidiana, Z.; Qualitative Spaces: Integrating Spatial Analysis for a Mixed Method Approach [Online] 2017 [Cited 2021 Mar 3] Available from: https://www.researchgate.net/publication/282920187_Qualitative_Spaces_Integrating_Spatial_A nalysis_for_a_Mixed_Methods_Approach 